\title{
Mass Casualty Triage: An Evaluation of the Data and Development of a Proposed National Guideline
}

\author{
E. Brooke Lerner, PhD, Richard B. Schwartz, MD, Phillip L. Coule, MD, Eric S. Weinstein, MD, \\ David C. Cone, MD, Richard C. Hunt, MD, FACEP, Scott M. Sasser, MD, \\ J. Marc Liu, MD, Nikiah G. Nudell, NREMT-P, CCEMT-P, Ian S. Wedmore, MD, \\ Jeffrey Hammond, MD, MPH, Eileen M. Bulger, MD, Jeffrey P. Salomone, MD, \\ Teri L. Sanddal, BS, NREMT-B, Graydon C. Lord, MS(c), NREMT-P, \\ David Markenson, MD, FAAP, EMT-P, and Robert E. O'Connor, MD, MPH
}

\section{ABSTRACT}

Mass casualty triage is a critical skill. Although many systems exist to guide providers in making triage decisions, there is little scientific evidence available to demonstrate that any of the available systems have been validated. Furthermore, in the United States there is little consistency from one jurisdiction to the next in the application of mass casualty triage methodology. There are no nationally agreed upon categories or color designations. This review reports on a consensus committee process used to evaluate and compare commonly used triage systems, and to develop a proposed national mass casualty triage guideline. The proposed guideline, entitled SALT (sort, assess, life-saving interventions, treatment and/or transport) triage, was developed based on the best available science and consensus opinion. It incorporates aspects from all of the existing triage systems to create a single overarching guide for unifying the mass casualty triage process across the United States. ～(Disaster Med Public Health Preparedness. 2008;2(Suppl 1):S25-S34)

Key Words: triage, trauma and injury, emergency medical services

$\mathrm{T}$ he original concept and advancement of mass casualty triage has largely resulted from the need of militaries to efficiently and effectively treat multiple battle casualties. ${ }^{1,2}$ Many of the strategies used to triage and treat wounded soldiers have been advocated for the civilian setting, and the ability of civilian emergency medical services (EMS) providers to prioritize patients for treatment and transport during a mass casualty incident is viewed as an essential skill. However, within the United States, the specific system of mass casualty triage that a prehospital care provider learns to use has been dependent largely on local or regional protocols, with little consistency or interoperability between jurisdictions. Large scale disasters require cross-jurisdictional cooperation and highlight the need for a national, standardized approach to mass casualty triage.

Triage occurs at different times, performed by different types of health care providers for a variety of reasons during the provision of emergency care. Examples range from emergency medical technicians determining whether an injured patient needs to be transported to a trauma center, to emergency department nurses determining which patient needs to be placed in a treatment room first. These decisions incorporate much of the same information as is used for mass casualty triage and are made by most emergency providers every day. However, during mass casualty triage the decisions must be made more rapidly, leaving providers with less time to gather the information upon which to base their decisions. Furthermore, in the mass casualty situation, the emphasis shifts from ensuring the best possible outcome for each individual patient to ensuring the best possible outcome for the greatest number of patients. In the United States, outside of drills or other artificial training scenarios, EMS providers rarely have the opportunity to make mass casualty triage decisions.

The new emphasis on community preparedness in the United States has led to greater efforts to improve and develop local EMS providers' skills in mass casualty triage, including tremendous investments of time and money. Unfortunately, many communities have had little assistance in appraising the myriad triage systems that are available on the market. Many of these systems use only slightly modified criteria for assigning triage priorities and are based on proprietary tagging systems. Selecting the proper triage instrument is not an inconsequential decision. In a synthesis of available evidence, Frykberg ${ }^{3}$ found that during a mass casualty incident there is a nearly linear relation between overtriage and poor patient outcome.

This project enlisted a multidisciplinary committee (see Appendix) to review the available triage systems and evaluate the scientific evidence available for each system. The committee was then charged with determining whether a national guideline could be developed for mass casualty triage that would allow interoperability between jurisdictions and systems. In general, the committee worked to identify a standardized set of triage priority 
categories and color designations, as well as a suggested methodology for assigning primary triage categories to patients during a mass casualty incident.

\section{COMMITTEE METHODS}

The committee conducted their work through a series of conference calls and 2 face-to-face meetings. Initially, a list of all mass casualty triage systems was generated and reviewed by all of the members to ensure it was complete. Each member was assigned a triage system and asked to conduct an exhaustive literature review and develop a report of the system for the group. This review included peer-reviewed publications as well as other types of reports. Each system had 2 or more members assigned to conduct a review. The reviews were presented to the group and a grid was developed that described each system in regards to several parameters (eg, color codes, training time and costs, when a patient is designated as dead).

\section{EXISTING TRIAGE SYSTEMS}

The committee identified 9 existing mass casualty triage systems, including 2 pediatric-specific systems (Table 1 ). These systems have been described in detail elsewhere, ${ }^{4}$ and are relatively similar in that most use a 4- or 5-category scheme that is based on basic physiological criteria. A notable exception is the Sacco Triage Method, which uses a proprietary computer-based algorithm to generate a numeric treatment priority score based on physiological criteria and available community resources.

These systems also vary in whether an "expectant" category is available for patients who have injuries that are unlikely to be survivable given available resources, as well as in which physiological criteria should be used during the triage process and how these criteria should be measured.

Several secondary triage tools, such as Secondary Assessment of Victim Endpoint triage and System of Risk Triage, also were identified but not evaluated because this project focused on primary triage only. Although it was recognized that primary triage constitutes only the initial part of the triage process during a mass casualty incident, the committee was charged with being focused in its review.

The Move, Assess, Sort, Send (MASS) Triage system as presented in the National Disaster Life Support suite of courses was also examined. ${ }^{13}$ This triage system allows the use of any triage categorization system, but provides guidance on the process of evaluating patients at the scene. The MASS system recognizes the need for an initial global sorting of patients before individual assessment. This is done in the move stage by asking ambulatory patients to go to a specific location and then asking those who cannot move to wave their hands. The rescuer then goes first to those patients who are not moving or waving to conduct an individual assessment. This individual assessment is then used to categorize patients into 1 of 4 categories: immediate, delayed, minimal, or expectant, or they are identified as deceased. $\mathrm{Pa}$ tients are then sorted into their respective categories to stage for transport. Once this is complete, patients have been prioritized for transport and should be sent to an appropriate receiving facility.

The French red and white plans also were reviewed, and it was determined that these plans were global response plans. However, they do provide some insight into the French approach to the primary triage of patients. ${ }^{14}$ The French approach involves bringing patients from the scene to a field triage unit for evaluation, and then moving patients to a hospital based on the assessment that takes place in the field unit. This assessment places patients in 1 of 3 categories: absolute emergency, relative emergency, and involved. The committee determined that this was different from the process in the United States, where primary priority decisions are made by the providers at the scene. Furthermore, the French system requires providers with different skill sets (eg, physicians staff the field hospital) than are currently used in the field in the United States.

\section{EXISTING SCIENTIFIC EVIDENCE \\ Anecdotal Reports}

There are numerous anecdotal reports of triage systems being used during mass casualty events documenting both successes and failures, ${ }^{15-21}$ including cases in which no formal triage was done at all. ${ }^{18}$ Unfortunately, it is difficult to ascertain the causes of these successes and failures because of the anecdotal nature of these reports. The impact of the triage system itself versus other factors-such as training, availability of triage equipment, application of the triage tags, or some other unknown factor-cannot be satisfactorily determined.

\section{Predictive Ability of Physiological Criteria}

Conducting clinical research on the optimal response to a disaster prospectively is difficult, if not impossible. Having sufficient data to evaluate disaster responses retrospectively also can be challenging due to the limited frequency of events and the poor quality of the records that are maintained. A potential surrogate is to study the characteristics of trauma patients who sustain injuries from mechanisms that are not the result of a mass casualty incident. This information is not ideal but can be informative in considering methods for triaging mass casualties.

In particular, the usefulness of certain physiological measurements in predicting which patients need immediate assis- 


\section{Comparison of Existing Mass Triage Systems}

\section{System}

Simple Triage and

Rapid Treatment $(\mathrm{START})^{5}$

Jump START ${ }^{6}$

Homebush $^{7}$

Triage Sieve $e^{8,9}$

Pediatric Triage Tape $(\mathrm{PTT})^{10}$

\section{Coding}

Immediate: red

Delayed: yellow

Walking wounded: green

Deceased: black

Immediate: red Delayed: yellow

Minor: green

Deceased: black

Immediate: red

Urgent: yellow/gold

Not urgent: green

Dying: white

Dead: black

Also assigned radio voice categories:

Immediate: A (alpha)

Urgent: B (bravo)

Not urgent: C (charlie)

Dying: D (delta)

Dead: E (echo)

Priority 1 (immediate): red

Priority 2 (urgent): yellow Priority 3 (delayed): green

Priority 3: walking

Priority 4 (expectant): blue

Dead: white or black

Immediate: red

Urgent: yellow

Delayed: green

Dead

\section{Status Assigned Based on}

Immediate: respiratory rate $>30$, slow capillary refill, or cannot follow commands

Walking wounded: able to walk

Deceased: not breathing after 1 attempt to open airway

Delayed: all other patients Immediate: respiratory rate $<15,>45$, or irregular; or no palpable peripheral pulse; or inappropriate posturing or unresponsive ( $P$ or $U$ on AVPU scale)

Delayed: unable to walk, regular respiratory rate 15-45; and palpable peripheral pulse; and $\mathrm{A}$ or $V$ on AVPU scale

Minor: able to walk

Dead: not breathing after 1 attempt to open airway and 5 rescue breaths

Not urgent: anyone who can walk

Dead: not breathing

Dying: patients assessed as being beyond help

Immediate: not walking breathing, but not able to follow commands, or no radial pulse, or respiratory rate $>30$

Urgent: nonambulatory patients who do not meet other criteria

Priority 1: not walking with respiratory rate $<10$ or $>29$; or capillary refill $>2$ sec

Priority 2: not walking with a respiratory rate $10-29$ and capillary refill $<2 \mathrm{sec}$

Dead: no airway

Immediate: abnormally slow or fast respiratory rate; or an abnormally slow or fast pulse rate

Urgent: not walking with a capillary refill $<2 \mathrm{sec}$

Delayed: child that is walking; or an infant that is alert and moving all limbs

Dead: not breathing
Permitted Therapies Before Assigning to Dead Category

1 attempt to open the airway through positioning

Open the airway using basic positioning: If there is still on breathing and there is a palpable radial, give 5 rescue breaths

Reassess after Immediate and Delayed children have been taken care of

One attempt to open airway using basic positioning methods

Open airway

Does not breathe after airway is opened by jaw thrust

\section{Comments}

1. Modified version replaces capillary refill with no palpable radial pulse
1. Developed for pediatric patients 1-8 y old

2. Developed to parallel structure of START triage system

3. If a child is carried to ambulatory area he or she should be first child assessed in that area

4. Has modification for nonambulatory children

1. Based on START and SAVE triage

2. Category for dying created so they can receive comfort care

3. Uses geographic triage with flags rather than individual tags

1. Heart rate of $>120$ bpm is substituted for capillary refill in cold conditions or poor light

2. Does not use mental status

1. Requires a tape that uses height of patient to show providers ageappropriate parameters that should be used to triage a child (provides for 4 sizes of children: $50-80$ $\mathrm{cm}, 80-100 \mathrm{~cm}$, 100-140 cm, and $>140 \mathrm{~cm}$ )

2. Adaptation of Triage Sieve

(Continued) 
TABLE 1

Comparison of Existing Mass Triage Systems

\begin{tabular}{|c|c|c|c|c|}
\hline System & Coding & Status Assigned Based on & $\begin{array}{l}\text { Permitted Therapies Before } \\
\text { Assigning to Dead Category }\end{array}$ & Comments \\
\hline CareFlite $^{11}$ & $\begin{array}{l}\text { Immediate: red } \\
\text { Urgent: yellow } \\
\text { Delayed: green } \\
\text { Unsalvageable: black }\end{array}$ & $\begin{array}{l}\text { Delayed: walks } \\
\text { Unsalvageable: not breathing } \\
\text { with an open airway } \\
\text { Immediate: doesn't follow } \\
\text { commands or no } \\
\text { palpable radial pulse } \\
\text { Urgent: does not walk but } \\
\text { obeys commands and } \\
\text { has a radial pulse }\end{array}$ & Open airway & $\begin{array}{l}\text { 1. No respiratory } \\
\text { considerations } \\
\text { 2. Can be used for } \\
\text { pediatric patients }\end{array}$ \\
\hline $\begin{array}{l}\text { Sacco Triage Method } \\
\text { (STM) }\end{array}$ & $\begin{array}{l}\text { Group 1: high rate of } \\
\text { deterioration } \\
\text { Group 2: moderate } \\
\text { Group 2: slow }\end{array}$ & $\begin{array}{l}\text { Assigns an RPM score } \\
\text { based on respiratory rate, } \\
\text { pulse rate, and motor } \\
\text { response }\end{array}$ & $\begin{array}{l}\text { No vital signs score } 0 \text { - } \\
\text { before scoring open } \\
\text { airway, decompress } \\
\text { pneumothorax, stop } \\
\text { exsanguination }\end{array}$ & $\begin{array}{l}\text { 1. Actually provides a } \\
\text { score for each } \\
\text { patient; grouping of } \\
\text { patients changes } \\
\text { with availability of } \\
\text { resources } \\
\text { 2. Transport order by } \\
\text { score not group }\end{array}$ \\
\hline Military Triage $^{12}$ & $\begin{array}{l}\text { Immediate } \\
\text { Delayed } \\
\text { Minor } \\
\text { Expectant }\end{array}$ & $\begin{array}{l}\text { Immediate: those who } \\
\text { should be treated first, } \\
\text { with a list of possible } \\
\text { injuries } \\
\text { Delayed: those who can } \\
\text { have a delay of } 6-8 \mathrm{~h} \\
\text { before treatment } \\
\text { Minor: those who will not } \\
\text { have significant mortality } \\
\text { if no further care is } \\
\text { provided } \\
\text { Expectant: those with signs } \\
\text { of impending death or } \\
\text { who require vast } \\
\text { resources for treatment }\end{array}$ & Open airway & $\begin{array}{l}\text { 1. Based on NATO } \\
\text { triage } \\
\text { 2. Secondary triage } \\
\text { includes system for } \\
\text { patient evacuation } \\
\text { 3. Colors are often } \\
\text { used to mark } \\
\text { casualties when they } \\
\text { have been triaged, } \\
\text { but colors can vary } \\
\text { from unit to unit and } \\
\text { are not universal }\end{array}$ \\
\hline CESIRA & $\begin{array}{l}\text { Red } \\
\text { Yellow } \\
\text { Green }\end{array}$ & $\begin{array}{l}\text { Red: unconscious, } \\
\text { hemorrhaging, in a state } \\
\text { of shock, insufficient } \\
\text { respirations, } \\
\text { Yellow: none of the above } \\
\text { with broken bones or } \\
\text { other injuries } \\
\text { Green: able to walk }\end{array}$ & $\begin{array}{l}\text { Not applicable: no dead } \\
\text { category }\end{array}$ & $\begin{array}{l}\text { 1. No dead category } \\
\text { because only } \\
\text { physicians can } \\
\text { declare death in Italy } \\
\text { 2. Based on presenting } \\
\text { problem } \\
\text { 3. Name is based on } \\
\text { order in which } \\
\text { conditions are } \\
\text { evaluated }\end{array}$ \\
\hline
\end{tabular}

AVPU, alert, voice, pain, unresponsive; SAVE, Secondary Assessment of Victim Endpoint; RPM, respiratory rate, pulse rate, and motor response; NATO, North Atlantic Treaty Organization.

tance has been considered. A recent Centers for Disease Control and Prevention (CDC)-sponsored review of the trauma triage guidelines used by EMS providers to determine which patients require a trauma center found that the physiological criteria of the Field Triage Decision Scheme were well supported. ${ }^{22,23}$ This includes a Glasgow coma score of less than 14, a systolic blood pressure less than $90 \mathrm{mmHg}$, and a respiratory rate less than 10 or greater than 29 breaths per minute. These parameters are used, in some form, in most existing mass casualty triage systems.

Blood pressure is typically not a part of mass casualty triage systems because it would be difficult and time consuming to measure during an incident with a large number of patients. Instead, a palpable radial pulse or capillary refill of less than 2 seconds has typically been used as a surrogate measure to assess perfusion. It is important to recognize that some systems have moved away from using capillary refill time because it is impossible to measure in the dark and it can be inaccurate when the victim is cold or has been in contact with vasoconstricting or vasodilating agents (eg, during an incident in which a chemical agent is released). At least 1 study also has suggested that capillary refill is not an accurate predictor of hypovolemia. ${ }^{24}$

The Glasgow coma score is cumbersome for most providers to calculate in the field, particularly during the stress and time constraints of a major incident, and there is some literature to indicate that EMS providers may not accurately calculate the score for their individual patients. ${ }^{11,25}$ However, it has been suggested that the motor component of the Glasgow coma 
score, or more simply the ability to follow commands, is sufficient for identifying patients in need of immediate aid and/or rapid transport to a medical facility. This was shown by both Garner et $\mathrm{al}^{9}$ and Meredith et $\mathrm{al}^{26}$ using large numbers of trauma patients as the study sample.

\section{Validation of Specific Triage Systems}

The work group identified a limited number of publications that attempted to validate specific triage systems. There were few studies, but they are an important initial step in evaluating the existing systems.

The Simple Triage and Rapid Treatment (START) triage system was used during a 2002 train crash in the United States. Kahn et al ${ }^{27}$ retrospectively compared 132 patients' assigned triage codes to their ultimate outcome and found that 64 patients $(48 \%)$ were triaged correctly, 65 were overtriaged (49\%), and 3 were undertriaged (2\%). Two studies of START triage used written tests to evaluate whether provider triage skills improved with education. Risavi et al ${ }^{28}$ evaluated 109 providers and found the average pre-education test score was $55 \%$, and after a 2 -hour education session the average score increased to $75 \%$.

Baez et al ${ }^{29}$ evaluated 55 Latin-

American EMS providers using a Web-based education module and found that before the module 5 participants correctly triaged 4 or more of the 5 simulated patients, and after the education module 49 participants correctly triaged 4 or more of the patients.

JumpSTART, a variant of START for pediatric patients, also was evaluated using paper-based patient simulations in a study of 32 providers (emergency medical technicians and registered nurses) before and after receiving educational materials. The study found that of a possible 11 points on the paper-based scenarios, participants initially scored an average of 6.22 points. After the JumpSTART education was provided, the group scored an average of 8.25 points, and 3 months after the education they scored an average of 8.41 points. ${ }^{30}$ It is not known how well performance on a paper test predicts performance in the field.

A study of police officers using paper-based scenarios found that when given written educational materials on Triage Sieve and the Pediatric Triage Tape, the officers did significantly better at triaging patients with the educational materials than without. ${ }^{31}$ They correctly triaged $80 \%$ of the patient scenarios with the materials and only $60 \%$ without. The Pediatric Triage Tape also was evaluated by applying it to 3461 children who presented to a South African trauma unit to determine whether it accurately identified patients with an Injury Severity Score $>15 .^{32}$ They found that the tape had a sensitivity of 38\% and specificity of $99 \%$. If it had been used, $39 \%$ of children would have been overtriaged and $4 \%$ would have been undertriaged.

\section{COMPARISONS BETWEEN TRIAGE SYSTEMS}

Three studies were identified that compared the various mass casualty triage systems to each other. Garner et $\mathrm{al}^{9}$ conducted an analysis of 1144 trauma patients who were retrospectively assigned triage categories using the Triage Sieve, START, and CareFlite triage methods. They found that the Triage Sieve had the lowest sensitivity $(45 \%, 95 \%$ confidence interval [CI] 37\%-54\%) and START had the highest sensitivity $(85 \%, 95 \%$ CI $78 \%-90 \%)$. The sensitivity of CareFlite (82\%, 95\% CI 75\%-88\%) was similar to that of START. The specificity was highest for CareFlite at 96\% (95\% CI 94\%-97\%) compared with Triage Sieve at 89\% (95\% CI $87 \%-91 \%$ ) and START at 86\% (95\% CI 84\%-88\%). Furthermore, they found that the ability to obey commands and systolic blood pressure were the best predictors of critical injuries in these patients. The study, however, was limited by its sample, which consisted of patients with a variety of mechanisms of injury, but none that were the result of an explosion or other mass casualty incident.

The creators of the Sacco Triage Method used simulation to compare their method to START triage using a test dataset of patients with blunt trauma from the Pennsylvania Trauma Systems Foundation and outcomes determined by 6 trauma care experts who came to consensus using the Delphi technique. ${ }^{33}$ They found that the assessment of each patient with START took about 30 seconds, whereas the Sacco method took 45 seconds. They concluded that the Sacco method had greater expected survivorship compared with START. They had similar conclusions when using similar methods to compare the 2 triage systems for patients with penetrating trauma. ${ }^{34}$ Although these results are promising, it must be noted that the same committee was used to develop the rule as was used to validate the rule, and both were based on a trauma registry of patients who sustained injuries that did not result from mass casualty events. Furthermore, the consensus committee's assessment of survival time and treatment need was based solely on a secondary database review.

Triage systems for pediatric patients were compared in a study by Wallis and Carley, ${ }^{35}$ which evaluated 3461 patients presenting to an emergency department in South Africa. They prospectively scored each injured patient using the Pediatric Triage Tape, CareFlite, START (for patients older than 8 years), and JumpSTART (for patients younger than 8 years old), then followed the patients to determine the actual 
severity of their injuries. Using an Injury Severity Score $>15$ as the outcome, CareFlite had the greatest sensitivity at $48.4 \%$ compared with the Pediatric Triage Tape $(37.8 \%)$, START $(31.3 \%)$, and JumpSTART (3.2\%). CareFlite also had the greatest specificity at $98.8 \%$ compared with the Pediatric Triage Tape (98.6\%), START (77.9\%), and JumpSTART (97.8\%). These measurements were made by the same providers over the course of several months. Therefore, they had more experience than the average provider. Furthermore, they were made in the relatively less stressful and less austere emergency department environment, rather than at the scene of a major incident.

\section{DEVELOPMENT OF THE COMMITTEE'S POSITION}

The committee concluded that based on the available evidence, no one system could be embraced as a validated system that could be used as a national guideline for mass casualty triage. CareFlite had the best support in the literature, but it had only been tested using emergency department patients who had not been involved in a mass casualty incident. The committee felt that it was possible to use the best available scientific information and consensus opinion to develop a system that could serve as a proposed national guideline for mass casualty triage, recognizing that this would be limited by the lack of available scientific data. This was done by using the grid of existing systems to generate a list of key components for a triage system. Each component was discussed by the group until consensus was reached. The guideline that was developed incorporated pieces of most of the existing triage system; because of this it was given the name SALT Triage (Fig. 1). SALT stands for sort, assess, lifesaving interventions, and treatment and/or transport. This guideline is intended to be used for all-hazards events and be applicable in both adults and children. It describes 4 activities: global sorting of patients using voice commands, lifesaving interventions that can be quickly applied, individual assessment and assignment of a priority category, and provision of treatment and/or transport.

\section{Global Sorting}

Most systems begin the triage process by identifying those who are able to walk. In most cases, these patients are triaged as minimally injured. This decision is based on the fact that a patient who can follow the command to walk illustrates that they have sufficient cerebral perfusion, and are likely to have a palpable radial pulse or a fast capillary refill, and they are demonstrating the ability to follow commands.

Many critics have noted that this group may still have injuries that need immediate or delayed treatment. Furthermore, it is widely believed and anecdotally reported that many casualties will leave the scene and take themselves to a health care facility during a mass casualty incident, causing the closest facilities to the incident to be overwhelmed with these patients before the more severely injured patients arrive. ${ }^{36-38}$ To address these issues, a global sorting of patients was included in SALT Triage, similar to what is recommended in the move stage of the MASS Triage system. Simple voice commands are used to prioritize patients for individual assessment and to give those who can walk clear instructions regarding where to go for help. These instructions may keep casualties from self-triaging to the closest

\section{FIGURE}

Proposed national triage guideline: SALT mass casualty triage.

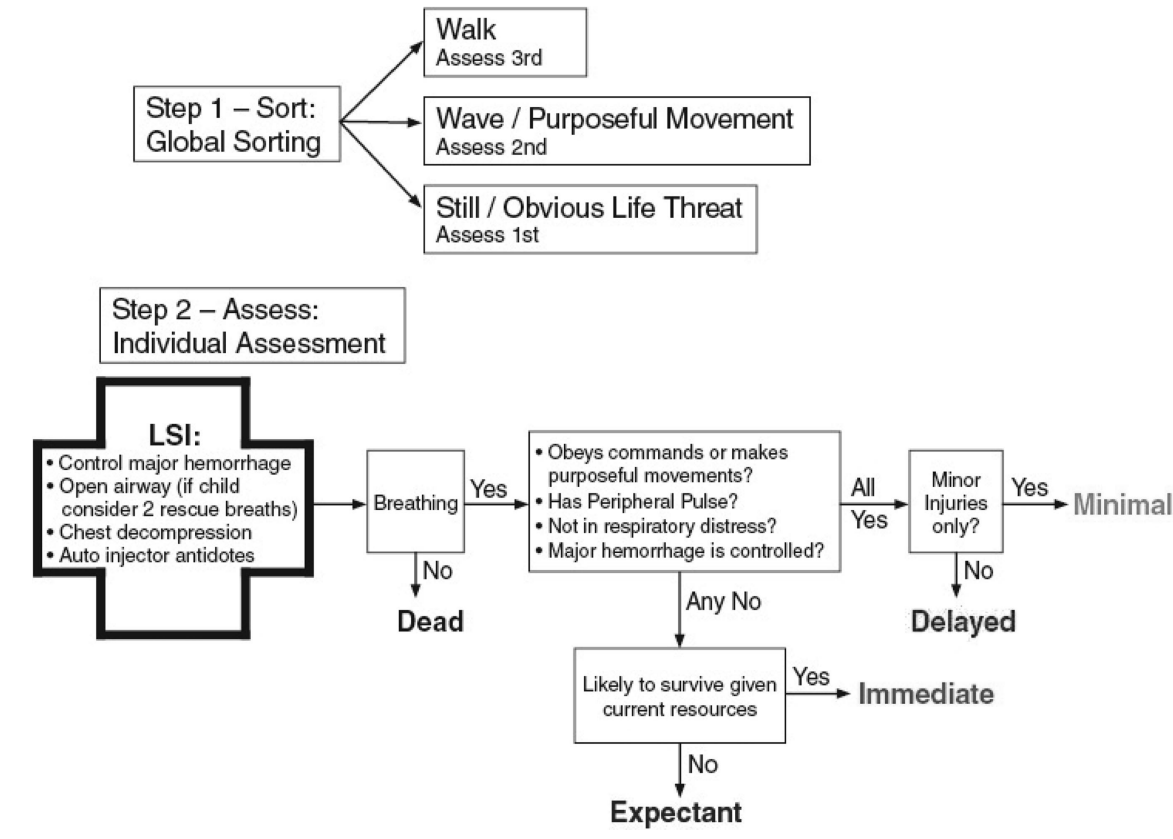


hospital by giving them a specific place to go for additional assistance.

The committee determined that those who could walk should be prioritized as last for individual assessment, and not simply assigned to a minimally injured category without further evaluation. The wave command used in MASS casualty triage also was adopted to further prioritize those patients who remain at the site. Incorporating a wave command into the global sorting process allows the provider to distinguish those patients who are not able to follow a command from those who are not physically able to walk but can still follow a command. By assessing those patients who are not waving or making purposeful movements first (ie, those not able to follow commands), the provider is likely to approach those patients who may require lifesaving interventions first. We recognize that certain patients (people with impaired hearing, very young people, and individuals with mental disabilities) may be inappropriately prioritized first for individual assessment using the walk and wave commands, but this would be acceptable and would likely not involve excessive numbers of patients.

The guideline suggests that those who can wave or are making purposeful movements should be individually assessed second. However, because a patient with uncontrolled hemorrhage who can follow commands may be prioritized second and exsanguinate while awaiting attention, the committee included those with obvious uncontrolled hemorrhage in the group that should be assessed first. This ensures that these patients receive timely hemorrhage control.

\section{Lifesaving Interventions}

All of the analyzed triage systems allow for providing lifesaving interventions during the initial triage process. Specifically, all of the systems included opening the airway using basic interventions before assigning the patient to the "dead" category. In the SALT Triage guideline, providing lifesaving interventions is a formal process that is completed before assigning a triage category. Lifesaving interventions should be provided quickly and only if needed supplies are readily available and the provider is trained in their use. The committee agreed that lifesaving interventions should include control of major hemorrhage, opening the airway, provision of 2 rescue breaths for child casualties, decompression of tension pneumothorax, and use of autoinjector antidotes. These interventions were selected because they can be applied rapidly and can have a profound impact on survival, although data regarding actual application in mass casualty settings are lacking. JumpSTART recommends that 5 rescue breaths be given to children. The committee reduced this to 2 to be consistent with the American Heart Association cardiopulmonary resuscitation guidelines, allowing easier recall and taking less time to perform.

\section{Assigning Triage Categories}

As shown in Figure 1 and Table 1, the SALT Triage guideline for assigning specific triage categories largely parallels the process established by the existing triage systems. The major difference is that this process includes an expectant category, and we recommend the category be represented using the color gray. The expectant category is intended to be resource based and the definition could and should change depending on the magnitude of the incident, available resources, and the provider's level of training and comfort with using the category. The expectant category will be needed only if there are not enough resources available in the field to meet demand. This methodology allows providers to focus resources on potentially salvageable patients rather than applying resuscitation resources to those who are unlikely to survive.

The expectant category also is intended to be flexible and dynamic to ensure that should additional resources become available, it will be easy to find dying patients so that they can receive resuscitation or comfort care. Patients categorized as expectant should be readily identified, reevaluated frequently as resources become available, and have their triage categorization changed as appropriate.

Unlike the other triage categories (ie, immediate $=$ red, delayed $=$ yellow, minimal $=$ green, and dead $=$ black $)$, the color designation for expectant patients is not common among the existing mass casualty triage systems. Some systems use the color blue; however, that may potentially lead to confusion because blue also has been used to designate patients who need decontamination. In an effort to reflect the fluid nature of this category and to have a distinct color associated with it, the committee selected gray.

\section{DISCUSSION}

This project was undertaken because standardization of triage methodology, techniques, and category names across agency and jurisdictional lines in the United States can intuitively be expected to decrease confusion, ensure timely and accurate care in the field, and improve destination decision making. It is common for disasters to cross multiple jurisdictional lines and/or require additional responders to be deployed from across the country, and thus a national standard will allow all responders to use the same language and processes. Furthermore, this guideline is intended to be an all-hazards mass casualty initial triage guideline for all patients (eg, adults, children, special populations). The committee recognized that many EMS 
systems already have invested in mass casualty triage tagging systems and provider training. For most systems, only minor changes would be needed to make them compatible with this proposed national guideline because it is based on the existing systems.

Some may feel that this process simply creates a new triage system that, like the others, is not validated. However, this proposed national guideline includes what is believed to be the best components of the existing triage systems. It was developed after critical evaluation of the existing literature by a multidisciplinary panel. A standardized guideline was created that is based on existing mass casualty triage systems, incorporating available scientific data, and when there is insufficient data, incorporating the panel's opinion. The committee recognizes the paucity of scientific evidence with regard to mass casualty field triage and recognizes the need for further research in disaster field triage, the validation of the proposed SALT Triage guideline, and adjustment of this proposed national guideline as more scientific data becomes available. This will require the development of a sustainable mechanism for this process, including the identification of a body that will be responsible for periodically reviewing new and available literature, advocating for further research, and incorporating new findings and updates into the SALT Triage guidelines. At this juncture, this process has not yet been established.

Training systems need to be created for SALT Triage, but it is the committee's expectation that responders of all levels could be trained to use the SALT Triage guideline; the individual patient assessment is designed to be used by people with any level of training. Furthermore, because there is an emphasis on continual reevaluation, as additional responders arrive on scene they will be able to re-sort and refine the triage decisions that initial providers have made.

\section{Limitations and Future Directions}

There is no existing measure against which to judge the accuracy or appropriateness of mass casualty triage decisions in either the trauma or disaster literature. This lack of a universally accepted measure of triage accuracy makes it difficult to evaluate triage systems. The medical and scientific communities must develop a consensus position on how to determine whether triage decisions are "correct." Once a consensus is reached, mass casualty triage systems will be able to achieve a broader and more reliable scientific base and true advancements will be possible in mass casualty triage.

Triage decisions cannot be made in isolation and must be made considering the availability of resources. Responding to 30 victims with 4 ambulances is different from responding with 16 ambulances and numerous responders. Furthermore, there is no differentiation of patients in most primary triage systems once they are placed in large categories (ie, immediate, delayed, minimal, and expectant). Clearly, within those categories some patients will need treatment sooner than others. As stated in the introduction, SALT Triage only addresses primary triage, the initial sorting of patients into relatively large categories that allow responders to organize their initial response to a mass casualty incident. The decision of whom to treat and/or transport first and how best to use the resources on hand requires additional discussion and evaluation. Triage methods that take into account resource availability may also be important, particularly because alternate transport vehicles, such as buses, or transport of minor or delayed patients with immediate patients can be important yet complicated parts of the process of evacuating casualties from a scene. More work is needed in this area before any recommendation can be made and incorporated into the SALT Triage guideline.

Using limited resources to treat casualties with little chance of survival may negatively affect the outcome of patients with time-dependent injuries who are forced to wait for additional resources. This is a difficult part of mass casualty triage, especially because during normal conditions the goal of all EMS providers is to do everything to achieve the best possible outcome for each patient. Given the resource constraints of a mass casualty triage situation, the goal must change to do the most good for the greatest number of people. The committee felt that to achieve this change in standards, an expectant category had to be included in the SALT Triage guideline. The expectant category is intended to be resourcebased and the definition will change depending on the situation and the available resources. It is only needed if there are not enough resources at the scene to meet demand and it requires the provider to consider the probable prognosis of the patient. This may be difficult for the first responder, in which case the category can be withheld and those patients would be tagged as immediate until a more advanced level provider is available to reevaluate the patient. This does add a level of complexity, but the expectant category allows providers to focus resources on potentially salvageable patients rather than applying resuscitation resources to those who are unlikely to survive.

A patient's condition may deteriorate or improve over time. Therefore, the triage finding at 1 point in time may not be accurate at a later time. Triage should be conducted as a dynamic process and prioritization should be altered by changing patient conditions, resources, and scene safety.

Training in and maintenance of mass casualty triage skills is a final area that still requires a great deal of consideration and development. Providers are infrequently able to use mass casualty triage protocols and thus may not be as proficient in this skill as they are with other skills that they use regularly. This committee did not attempt to address this issue other than to make the SALT Triage guideline as simple as possible 
and applicable to all patients in all situations, including small events (eg, multiple-patient car crashes).

Finally, although this system is intended for all-hazard responses, it will work only when there is a common scene where all casualties are present at a single point in time. It will not work for a large-scale biological incident in which patients will present during different periods of time and in numerous locations.

\section{CONCLUSIONS}

This project has established a proposed national guideline for primary mass casualty triage. It is intended to help standardize the approach among first responders and to be a foundation that can be further developed by the expertise of those knowledgeable in the medical and scientific aspects of mass casualty triage. It addresses only a small portion of the triage process during a mass casualty incident, but should help provide clarity in the critical initial evaluation of multiple casualties. Its creators see it as a beginning rather than a final product.

\section{APPENDIX: WORK GROUP PARTICIPANTS}

Selected by the American College of Emergency Physicians: Eric S. Weinstein, MD

Selected by the American Medical Association: Phillip Coule, MD; Ray Swienton, MD

Selected by the American College of Surgeons Committee on Trauma: Jeffrey Hammond, MD, MPH; Jeffrey Salomone, MD; Eileen Bulger, MD; Sharon Henry, MD; Howard Taekman, MD

Selected by the National Association of Emergency Medical Technicians: Graydon "Gregg” Lord; David Markenson, MD

Selected by the National Association of State Emergency Medical Service Officials: Wayne Misselbeck, MD; Nick Nudell; Joseph Schmider

Selected by the National Association of EMS Physicians: David Cone, MD; E. Brooke Lerner, PhD; Robert E. O'Connor, MD, MPH; Richard Schwartz, MD; Colonel Ian Wedmore, MD; J. Marc Liu, MD (fellow)

Selected by the Native American Emergency Medical Services Association: Teri Sanddal, BS, NREMT-B

Additional participants who attended the work group meetings:

Bob Bailey, CDC

Richard Hunt, MD, CDC

Scott M. Sasser, MD, Emory University School of Medicine,

Centers for Disease Control and Prevention

Jon Krohmer, MD, Department of Homeland Security

Tasmeen Singh, Emergency Medical Services for Children

Gamunu Wijetunge, National Highway Traffic Safety Administration

David Marcozzi, MD, MHS-CL, Office of the Assistant Secretary for Preparedness and Response

\section{About the Authors}

Drs Lerner and Liu are with the Department of Emergency Medicine, Medical College of Wisconsin; Drs Schwartz and Coule are with the Department of Emergency Medicine, Medical College of Georgia; Drs Weinstein and Cone are with the Department of Surgery, Section of Emergency Medicine, Yale University School of Medicine; Drs Hunt and Sasser are with the Division of Injury Response, National Center for Injury Control and Prevention, CDC; $\mathrm{Mr}$ Nudell is with the Idaho EMS Bureau, Boise, ID; Dr Wedmore is with the Department of Emergency Medicine, Madigan Army Medical Center; Dr Hammond is with the Robert Wood Johnson Medical School; Dr Bulger is with the Department of Surgery, University of Washington; Dr Salomone is with the Division of Trauma/Surgical Critical Care, Department of Surgery, Emory University School of Medicine; Ms Sanddal is with the Critical Illness $\mathcal{E}^{2}$ Trauma Foundation; Mr Lord is with the Homeland Security Policy Institute, The George Washington University; Dr Markenson is with the Center for Disaster Medicine, New York Medical College; and Dr O'Connor is with the Department of Emergency Medicine, University of Virginia Health System.

Address correspondence and reprint requests to E. Brooke Lerner, PhD, Department of Emergency Medicine, Medical College of Wisconsin, $9200 \mathrm{~W}$ Wisconsin Ave, Milwaukee, WI 53226 (e-mail: eblerner@mcw.edu).

Received for publication March 11, 2008; accepted June 4, 2008.

\section{Authors' Disclosures}

The authors report no conflicts of interest.

\section{Acknowledgments}

This study was supported by the Department of Health and Human Services, CDC, program 02195, "Terrorism Injuries: Information Dissemination and Exchange," award No. U38/CCU324162-01-03. Dr Lerner was partially supported by CDC grant R49/CE001175. Dr Liu was supported by the NAEMSP-Zoll EMS Resuscitation Fellowship. The findings and conclusions in this report are those of the authors and do not necessarily represent the views of the CDC.

ISSN: 1935-7893 (C) 2008 by the American Medical Association and Lippincott Williams \& Wilkins.

DOI: 10.1097/DMP.0b013e318182194e

\section{REFERENCES}

1. Hoey BA, Schwab CW. Level I center triage and mass casualties. Clin Orthop Relat Res. 2004;(422):23-29.

2. Kennedy K, Aghababian RV, Gans L, et al. Triage: techniques and applications in decision making. Ann Emerg Med. 1996;28:136-144.

3. Frykberg ER. Medical management of disasters and mass casualties from terrorist bombings: how can we cope? J Trauma. 2002;53:201-212.

4. Jenkins JL, McCarthy ML, Sauer LM, et al. Mass-casualty triage: time for an evidence-based approach. Prehosp Disaster Med. 2008;23:3-8.

5. Benson M, Koenig KL, Schultz CH. Disaster triage: START, then SAVE - a new method of dynamic triage for victims of a catastrophic earthquake. Prehosp Disaster Med. 1996;11:117-124.

6. Romig L. The JumpSTART Pediatric MCI Triage Tool. 2008. http:// www.jumpstarttriage.com/JumpSTART_and_MCI_Triage.php. Accessed February 10, 2008.

7. Nocera A, Garner A. An Australian mass casualty incident triage system for the future based upon triage mistakes of the past: the Homebush triage standard. Aust NZ J Surg. 1999;69:603-608.

8. Hines S, Payne A, Edmondson J, et al. Bombs under London. The EMS response plan that worked. JEMS. 2005;30:58-67.

9. Garner A, Lee A, Harrison K, et al. Comparative analysis of multiplecasualty incident triage algorithms. Ann Emerg Med. 2001;38:541-548.

10. Hodgetts T, Hall J, Maconochie I, et al. Paediatric triage tape. Pre-hospital Immediate Care. 1998;2:155-159. 
11. Kerby JD, MacLennan PA, Burton JN, et al. Agreement between prehospital and emergency department Glasgow coma scores. J Trauma. 2007;63:1026-1031.

12. Wiseman DB, Ellenbogen R, Shaffrey CI. Triage for the neurosurgeon. Neurosurg Focus. 2002;12:E5.

13. Coule P, Dallas C, James J, et al, eds. Basic Disaster Life Support (BDLS) Provider Manual. Chicago: American Medical Association; 2003.

14. Carli P, Telion C, Baker D. Terrorism in France. Prehosp Disaster Med. 2003;18:92-99.

15. Cook L. The World Trade Center attack. The paramedic response: an insider's view. Crit Care. 2001;5:301-303.

16. Asaeda G. The day that the START triage system came to a STOP: observations from the World Trade Center disaster. Acad Emerg Med. 2002;9:255-256.

17. Tran MD, Garner AA, Morrison I, et al. The Bali bombing: civilian aeromedical evacuation. Med J Aust. 2003;179:353-356.

18. Lee WH, Chiu TF, Ng CJ, et al. Emergency medical preparedness and response to a Singapore airliner crash. Acad Emerg Med. 2002;9:194-198.

19. Malik ZU, Pervez M, Safdar A, et al. Triage and management of mass casualties in a train accident. J Coll Phys Surg Pak. 2004;14:108-111.

20. Beyersdorf SR, Nania JN, Luna GK. Community medical response to the Fairchild mass casualty event. Am J Surg. 1996;171:467-470.

21. Wang T, Hung C. Appraisal of field triage in mass casualty incidents in Taipei. Ann Disaster Med. 2005;3:69-75.

22. American College of Surgeons. Resources for Optimal Care of the Injured Patient: 2006. Chicago: American College of Surgeons; 2006.

23. Lerner EB. Studies evaluating current field triage: 1966-2005. Prehosp Emerg Care. 2006;10:303-306.

24. Schriger DL, Baraff LJ. Capillary refill-is it a useful predictor of hypovolemic states? Ann Emerg Med. 1991;20:601-605.

25. Bazarian JJ, Eirich MA, Salhanick SD. The relationship between prehospital and emergency department Glasgow coma scale scores. Brain Inj. 2003;17:553-560.

26. Meredith W, Rutledge R, Hansen AR, et al. Field triage of trauma patients based upon the ability to follow commands: a study in 29,573 injured patients. J Trauma. 1995;38:129-135.

27. Kahn C, Schultz C, Miller K, et al. Does START triage work? An outcomes-level assessment of use at a mass casualty event. [abstract] Acad Emerg Med. 2007;14:S12a-S13a.

28. Risavi BL, Salen PN, Heller MB, et al. A two-hour intervention using START improves prehospital triage of mass casualty incidents. Prehosp Emerg Care. 2001;5:197-199.

29. Baez AA, Sztajnkrycer MD, Smester P, et al. Effectiveness of a simple Internet-based disaster triage educational tool directed toward LatinAmerican EMS providers. Prehosp Emerg Care. 2005;9:227-230.

30. Sanddal TL, Loyacono T, Sanddal ND. Effect of JumpSTART training on immediate and short-term pediatric triage performance. Pediatr Emerg Care. 2004;20:749-753.

31. Kilner T, Hall FJ. Triage decisions of United Kingdom police firearms officers using a multiple-casualty scenario paper exercise. Prehosp Disaster Med. 2005;20:40-46.

32. Wallis LA, Carley S. Validation of the paediatric triage tape. Emerg Med J. 2006;23:47-50.

33. Sacco WJ, Navin DM, Fiedler KE, et al. Precise formulation and evidence-based application of resource-constrained triage. Acad Emerg Med. 2005;12:759-770.

34. Sacco WJ, Navin DM, Waddell RK 2nd, et al. A new resource-constrained triage method applied to victims of penetrating injury. J Trauma. 2007; 63:316-325.

35. Wallis LA, Carley S. Comparison of paediatric major incident primary triage tools. Emerg Med J. 2006;23:475-478.

36. Waeckerle JF. Disaster planning and response. N Engl J Med. 1991;324: 815-821.

37. Hogan DE, Waeckerle JF, Dire DJ, et al. Emergency department impact of the Oklahoma City terrorist bombing. Ann Emerg Med. 1999;34:160-167.

38. Okumura T, Suzuki K, Fukuda A, et al. The Tokyo subway sarin attack: disaster management: I. Community emergency response. Acad Emerg Med. 1998;5:613-617. 